LIVER

\title{
Predictive value of arterial ammonia for complications and outcome in acute liver failure
}

\author{
V Bhatia, R Singh, S K Acharya
}

Gut 2006;55:98-104. doi: 10.1136/gut.2004.061754

See end of article for authors' affiliations

Correspondence to Dr S K Acharya, Room No 3065, 3rd floor, Teaching Block, All India of Medical Sciences, New Delhi 110029, India; subratacharya@ hotmail.com

Revised version received 5 June 2005

Accepted for publication 8 July 2005 Published online first 15 July 2005
Background and aim: In acute liver failure (ALF), the brain is exposed to high levels of ammonia. Human studies defining the clinical significance of ammonia in ALF are lacking. This prospective study evaluated the relationship of arterial ammonia levels at admission to complications and survival among patients with ALF.

Methods: Eighty consecutive ALF patients admitted from March 2001 to December 2003 were followed up until death or complete recovery. All had arterial ammonia estimation at admission (enzymatic method). Logistic regression analysis was performed to identify independent predictors of mortality.

Results: Forty two (52.5\%) patients died. Non-survivors had significantly higher median ammonia levels than survivors (174.7 v $105.0 \mu \mathrm{mol} / \mathrm{l} ; \mathrm{p}<0.001)$. An arterial ammonia level of $\geqslant 124 \mu \mathrm{mol} / \mathrm{l}$ was found to predict mortality with $78.6 \%$ sensitivity and $76.3 \%$ specificity, and had $77.5 \%$ diagnostic accuracy. Patients with higher ammonia levels also developed more complications, including deeper encephalopathy $(p=0.055)$, cerebral oedema $(p=0.020)$, need for ventilation $(p<0.001)$, and seizures $(p=0.006)$. Logistic regression analysis showed that $\mathrm{pH}$, presence of cerebral oedema, and arterial ammonia at admission were independent predictors of mortality (odds ratios 6.6, 12.6, and 10.9, respectively). Incorporating these variables, a score predicting mortality risk at admission was derived: $2.53+2.91$ ammonia +2.41 oedema $+1.40 \mathrm{pH}$, where ammonia is scored as 0 (if $<124 \mu \mathrm{mol} / \mathrm{l}$ ) or 1 (if $\geqslant 124 \mu \mathrm{mol} / \mathrm{l}$ ); oedema is scored as 0 (absent) or 1 (present); and $\mathrm{pH}$ is scored as 1 (if $\leqslant 7.40$ ) or 0 (if $>7.40$ ). Levels of partial pressure of ammonia were equally correlated with outcome.

Conclusion: Arterial ammonia at presentation is predictive of outcome and can be used for risk stratification. Ammonia lowering therapies in patients with ALF should be evaluated.
A mmonia neurotoxicity is an important component of cerebral dysfunction in patients with liver failure. ${ }^{1-4}$ Higher ammonia levels are found in patients with acute liver failure (ALF) compared with those with compensated and decompensated cirrhosis. ${ }^{5}$ The brain is exposed to high ammonia concentration in ALF, and unidirectional brain ammonia uptake has been well documented. ${ }^{1}$ Ammonia exposure induces multiple cellular abnormalities in the brain such as impaired bioenergetics and neurotransmission, astrocyte swelling, excitotoxicity, oxidative and nitrosative stress, and increased neuro-steroid biosynthesis. ${ }^{2-4}$

ALF has a high mortality with most non-survivors succumbing soon after admission. The natural course of the disease is often interrupted by liver transplantation and liver replacement therapies. Therefore, dissecting out the role of any single factor such as ammonia is difficult. Despite impressive progress at the molecular level, it is still not known if ammonia levels are related to cerebral dysfunction or patient outcome. To date, only one human study has reported that high ammonia levels among ALF patients are associated with subsequent cerebral herniation. ${ }^{5}$ If these observations are validated, use of ammonia lowering therapies in such patients would have a rational basis.

Ammonia predominantly exists in an ionised form $\left(\mathrm{NH}_{4}{ }^{+}\right)$ in the blood. Only a small $\mathrm{pH}$ dependent fraction, reflected by the partial pressure of ammonia $\left(\mathrm{pNH}_{3}\right)$, exists in a diffusible form. ${ }^{6}$ No data comparing total ammonia levels and $\mathrm{pNH}_{3}$ exist for ALF patients.

We therefore studied 80 conservatively managed ALF patients until recovery or demise, to determine the relationship between ammonia levels and patient outcome. We also created a mortality risk score by incorporating ammonia levels at admission, and compared the prognostic value of simultaneously estimated total ammonia levels and $\mathrm{pNH}_{3}$ levels.

\section{PATIENTS AND METHODS \\ Patients}

A total of 103 consecutive patients with ALF admitted to the gastroenterology ward of the All India Institute of Medical Sciences, New Delhi, during March 2001 to December 2003, were evaluated for inclusion. ALF was diagnosed according to the criteria laid down by the International Association for the Study of Liver. ${ }^{7}$ Twenty three patients were excluded because of diagnostic uncertainty at presentation or because of prior administration of ammonia lowering therapies, sedative drugs, or enteral alimentation. Hence a total of 80 patients with ALF were included in the study. In nine patients, arterial $\mathrm{pH}$ and ammonia levels could not be estimated in the same sample, and hence $\mathrm{pNH}_{3}$ levels were available for 71 ALF patients.

\section{Study variables}

ALF was defined by the occurrence of encephalopathy within four weeks of onset of symptoms in the absence of preexisting liver disease. ${ }^{7-9}$ The diagnosis was confirmed by the presence of submassive or massive necrosis in the post mortem liver biopsy specimen of patients who died.

Pre-encephalopathy and icterus encephalopathy periods were defined as the interval from the onset of prodrome and jaundice, respectively, to the onset of hepatic encephalopathy. ${ }^{8} 9$

Abbreviations: ALF, acute liver failure; $\mathrm{pNH}_{3}$, partial pressure of ammonia; $\mathrm{HCV}$, hepatitis $\mathrm{C}$ virus; $\mathrm{ROC}$, receiver operating characteristic; OR, odds ratio 
Admission to death interval was defined as the time interval from admission to death among non-survivors. Awake time was defined as the period between admission and improvement to grade 0 encephalopathy.

Grading of encephalopathy ${ }^{8}{ }^{10}$ was done as follows:

- Grade 1: loss of sleep rhythm, drowsiness, confusion, and flapping tremors.

- Grade 2: features of grade 1 encephalopathy with loss of sphincter control in addition.

- Grade 3: unconsciousness with no response to oral commands but responding to painful stimuli.

- Grade 4: deep unconscious state with no response to pain.

Cerebral oedema was defined clinically by the presence of spontaneous or inducible decerebrate posturing or by the presence of any two of the following: hypertension (blood pressure $>150 / 90 \mathrm{~mm} \mathrm{Hg}$ ), bradycardia, pupillary changes, or neurogenic hyperventilation. ${ }^{8}$

Infection was diagnosed by the presence of pyrexia (temperature $>101{ }^{\circ} \mathrm{F}$ ) or hypothermia (temperature $<98^{\circ} \mathrm{F}$ ) and neutrophil leucocytosis (total leucocyte count $>15$ 000/ $\mathrm{mm}^{3}$, with $\geqslant 80 \%$ polymorphs), and one or more of the following: positive blood culture, positive urine culture, or radiological evidence of pneumonitis. ${ }^{8}$

Renal failure was diagnosed if patients developed decreased urine output ( $<400 \mathrm{ml}$ in 24 hours), with serum creatinine $>1.5 \mathrm{mg} / \mathrm{dl}$ and blood urea $>40 \mathrm{mg} / \mathrm{dl}$, despite hydration, objectively assessed by central venous pressure of $10 \mathrm{~cm}$ of saline or more.

\section{Methods}

All patients were admitted to the gastroenterology intensive care unit and a uniform management protocol was followed. History was obtained from the attendants of the patient and a detailed clinical examination was performed at admission. All patients were subsequently evaluated every two hours. Each patient had continuous non-invasive cardiac oxygen saturation and blood pressure monitoring. Blood glucose was monitored two hourly. Neurological assessment was done once daily and on any sign of deterioration. The parameters noted were: grade of encephalopathy, presence of spontaneous or induced decerebration, pupillary size and reaction, and presence of any focal neurological deficit. Complete blood counts, biochemistry, and body fluid surveillance cultures were obtained daily.

Each patient was treated with prophylactic parenteral antibiotics (cefotaxime and cloxacillin), stress ulcer prophylaxis, and inotropic support, with the aim of maintaining mean arterial pressure at more than $60 \mathrm{~mm} \mathrm{Hg}$. Elective ventilation was used for all patients in grade 4 encephalopathy and those in grade 3 encephalopathy with evidence of cerebral oedema. Sedation or long acting muscle paralysing agents were not used in any patient. Cerebral oedema was managed conservatively by mannitol given in standard doses. Seizures were initially treated with diazepam and an additional mannitol bolus, followed by phenytoin.

Lactulose or other ammonia lowering therapies were not used in any case. Enteral feeding was not initiated in the initial three days in any patient. Liver transplantation and liver replacement therapies were unavailable and all patients were followed up until recovery or demise.

\section{Viral markers}

Serum samples from each patient were tested for hepatitis B surface antigen, $\operatorname{IgM}$ antibody against hepatitis B core antigen, and $\operatorname{IgM}$ antibody against hepatitis A virus using commercial immunosorbent assay (ELISA) test kits (Organon, Teknika, Netherlands). IgM antibody to ORF-1,
ORF-2, and ORF-3 of hepatitis E virus, and hepatitis E virus RNA were tested by methods developed at our institute. ${ }^{11}{ }^{12}$ Anti-hepatitis C virus (HCV) antibody was tested by using a third generation commercial ELISA (Xcyton, Bangalore, India) method. HCV-RNA was tested by reverse transcription nested polymerase chain reaction, using primers from the $5^{\prime}$ non-translated region, if appropriate, by methods described previously. ${ }^{11}{ }^{12}$

\section{Estimation of ammonia}

Arterial ammonia was estimated within 24 hours of admission by an enzymatic method (Randox Lab Ltd, UK) in heparinised plasma. The assay was based on the reaction of ammonia with $\alpha$-oxoglutarate in the presence of glutamate dehydrogenase to yield glutamate and $\mathrm{NAD}^{+}$. The normal ammonia value for the assay used was 10-47 $\mu \mathrm{mol} / \mathrm{l}$. Samples were obtained before the next dose of mannitol if possible, and with the ventilator settings unaltered for a minimum of one hour. The site of sampling was the radial artery in all cases. $\mathrm{pH}$ and bicarbonate levels were also obtained from the same sample. All samples were transported in ice and processed within 15 minutes.

Estimation of partial pressure $\left(\mathrm{pNH}_{3}\right)$ of ammonia ${ }^{13}$ Combining the mass balance equation and Henry's law, the formula for $\mathrm{p}\left[\mathrm{NH}_{3}\right]$ can be derived as:

$\left(\mathrm{p}\left[\mathrm{NH}_{3}\right]=\mathrm{K}_{\mathrm{H}} \times\left[\mathrm{NH}_{3}\right]_{\mathrm{T}}\right) /\left(1+\left[\mathrm{H}^{+}\right] / \mathrm{K}_{\mathrm{a}}\right)$

where $\left[\mathrm{NH}_{3}\right]_{\mathrm{T}}=$ total blood ammonia, $\mathrm{K}_{\mathrm{H}}$ for ammonia = $1.75 \times 10^{-5}, \mathrm{~K}_{\mathrm{a}}=9.8 \times 10^{-10}$, and $\left[\mathrm{H}^{+}\right]$is derived from the $\mathrm{pH}$ values, as antilog $(-\mathrm{pH})$.

\section{Data analysis and statistics}

Skewness of data distribution was checked before analysis. Median values and range are provided for skewed data. Survivors and non-survivors were compared using the MannWhitney $U$ test for continuous variables and the $\chi^{2}$ or Fishers test for discrete variables, wherever applicable. The level of

Table 1 Clinical and biochemical parameters among patients with acute liver failure $(n=80)$

\begin{tabular}{|c|c|}
\hline \multicolumn{2}{|l|}{ Parameter } \\
\hline $\begin{array}{l}\text { Age (y) } \\
\text { Encephalopathy grades 3, } 4 \text { (No (\%)) } \\
\text { Cerebral oedema (No (\%)) } \\
\text { Pre-encephalopathy interval (days) } \\
\text { lcterus encephalopathy interval (days) } \\
\text { Bilirubin (mg/dl) } \\
\text { Alanine aminotransferase (IU/I) } \\
\text { Albumin (mg/dl) } \\
\text { Prothrombin time increase (s) } \\
\text { Urea (mg/dl) } \\
\text { Sex (females) (No (\%)) } \\
\text { Pregnancy (No (\%)) } \\
\text { Ammonia ( } \mu \text { mol/l) } \\
\text { pNH }{ }_{3}\left(\times 10^{-5} \mathrm{~mm} \mathrm{Hg}\right) \\
\text { Lactate (mmol/I) } \\
\text { Bicarbonate (mEq/l) } \\
\text { Sodium (mEq/l) } \\
\text { Blood pH } \\
\text { Admission to death (days) } \\
\text { Awake time (days) } \\
\text { Aetiology } \\
\text { Post viral }{ }^{*} \\
\text { ATT induced } \\
\text { No evident cause }\end{array}$ & $\begin{array}{c}25.0(14-72) \\
58(72.5) \\
28(35.0) \\
6.0(2-29) \\
3.0(0-28) \\
14.1(3.9-42.0) \\
1115.0(122.0-7206.0) \\
2.7(1.6-4.5) \\
28.5(4-48) \\
16.0(14-90) \\
51(63.8) \\
20(39.2) \\
128.6(9.3-735.0) \\
6.28(0.26-41.06) \\
4.6(1.2-31.0) \\
20.0(5.9-32.2) \\
138.5(122.0-161.0) \\
7.49(7.02-7.80) \\
4.0(1-17) \\
4.0(1-12)\end{array}$ \\
\hline \multicolumn{2}{|c|}{$\begin{array}{l}\text { Quantitative data are given as median (range). } \\
\mathrm{pNH} \mathrm{H}_{3} \text {, partial pressure of ammonia; data for } 71 \text { patients. } \\
{ }^{*} \mathrm{Markers} \text { of acute hepatitis } \mathrm{A}, \mathrm{B} \text {, and/or } \mathrm{E} \text { viral infection }-71.8 \% \text { of } \\
\text { patients; isolated hepatitis } \mathrm{B} \text { surface antigen or anti-hepatitis } \mathrm{C} \text { virus } \\
\text { antibody }-9.9 \% \text { of patients; acute hepatitis } \mathrm{E} \text { infection, either alone or as } \\
\text { dual infection }-53.5 \% \text { of cases. }\end{array}$} \\
\hline
\end{tabular}


significance was set at $p=0.05$. A receiver operating characteristic (ROC) curve was made using the outcome variable as death and admission arterial ammonia levels as the independent variable to find out an appropriate cut off ammonia value for predicting mortality. ${ }^{14}$ Sensitivity, specificity, and odds ratio (OR) for the cut off value were also derived.

Univariate analysis of all relevant clinical and biochemical variables that may influence mortality was carried out. The significant variables were dichotomised using discriminant values derived by constructing ROC curves for each variable, and tested using forward stepwise logistic regression analysis taking a probability of 0.15 to enter the covariates into the model and 0.10 to exclude the covariate from the model. OR with 95\% confidence interval (95\% CI) and diagnostic accuracy for each predictor was calculated.

The predicted probability of outcome (mortality) was derived from the variables found to be significant on logistic regression analysis using the equation ${ }^{15}$ :

$$
\mathrm{P}_{\mathrm{X}}=1 /\left(1+\mathrm{e}^{-\mathrm{Z}}\right)
$$

where $\mathrm{P}_{\mathrm{X}}=$ probability of outcome (mortality),

$$
Z=\alpha+\beta_{1} X_{1}+\beta_{2} X_{2}+\beta_{3} X_{3} \ldots \ldots \ldots \beta_{n} X_{n}
$$

where $\alpha$ is the constant, $\beta$ is an unknown parameter, and $X$ $(\mathrm{l}-\mathrm{n})$ is the covariate.

An ROC curve for the predicted probability of death was made to derive area under the curve.

The $-2 \log$ likelihood ratios function for total ammonia and $\mathrm{pNH}_{3}$ were estimated from multivariate analysis of patients with available simultaneous estimations. The difference between the ratios was compared as the $\chi^{2}$ value at two degrees of freedom for the significance level. Statistical software SPSS (version 10; SPSS Inc., Chicago, Illinois, USA) and STATA (version 8.0) were used for statistical analysis.

\section{RESULTS}

Baseline clinical and biochemical characteristics of the patients, and aetiology of ALF are summarised in table 1. Over $80 \%$ of cases had a viral aetiology. Acute hepatitis E infection, either alone or as dual infection, was the most common cause $(53.5 \%$ cases).

Forty two $(52.5 \%)$ patients died. Median time from admission to death was 4.0 days (range 1-17). Awake time among survivors was 4.0 days (range $1-12$ days). Infection occurred in $47(58.8 \%)$ patients. Mechanical ventilation was required in $40(50.0 \%)$ cases. Raised blood urea levels ( $>40 \mathrm{mg} / \mathrm{dl})$ were present in 17 patients at admission. Of them, 12 normalised their renal parameters with hydration alone and five had renal failure. Overall, renal failure occurred in $11(14.1 \%)$ patients during the course of their

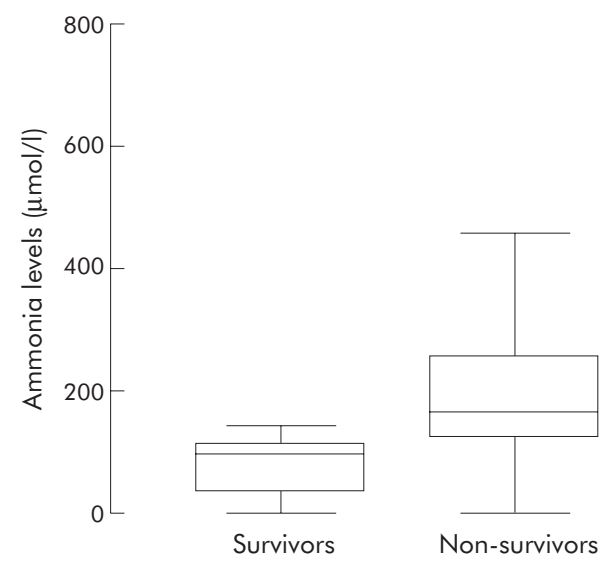

Figure 1 Comparison of arterial ammonia levels at admission between survivors and non- survivors among acute liver failure patients.

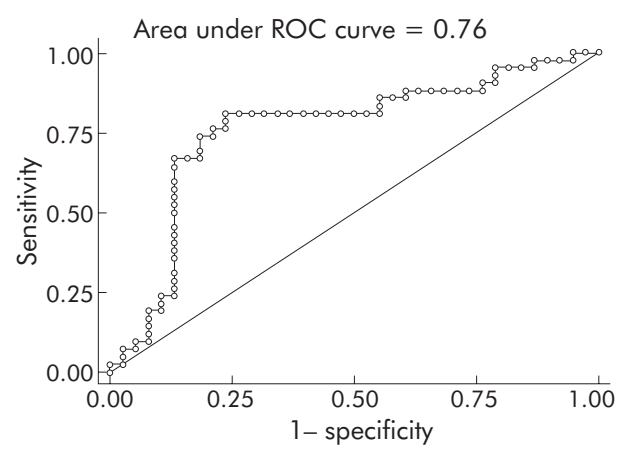

Figure 2 Receiver operating characteristic (ROC) curve of ammonia levels and mortality. Arterial ammonia levels $>124 \mu \mathrm{mol} / \mathrm{I}$ were $78.6 \%$ sensitive and $76.3 \%$ specific for predicting mortality.

illness, all of whom died. Ongoing uncontrolled infection was present in 10 of these patients.

\section{Ammonia levels at admission}

Median arterial ammonia level at admission was $128.6 \mu \mathrm{mol} / \mathrm{l}$ (range 9.3-735.0). Fifteen (18.8\%) patients had ammonia levels within the normal range $(<47 \mu \mathrm{mol} / \mathrm{l})$ at admission.

\section{Prognostic value of ammonia levels}

Median ammonia levels were significantly higher among non-survivors than survivors (174.7 $v 105.0 \mu \mathrm{mol} / \mathrm{l}$; $\mathrm{p}<0.001$ ), as shown in fig 1 . An ROC curve with ammonia levels of each patient as the independent variable and mortality as the outcome variable was made (fig 2). The area under the ROC curve was 0.76 (95\% CI 0.65-0.87). An arterial ammonia level of $\geqslant 124 \mu \mathrm{mol} / \mathrm{l}$ was found to be $78.6 \%$ sensitive and $76.3 \%$ specific for predicting mortality, with a diagnostic accuracy of $77.5 \%$. Thirty three $(78.6 \%)$ of 42 nonsurvivors and only nine $(23.7 \%)$ of 38 survivors had ammonia levels $>124 \mu \mathrm{mol} / \mathrm{l}$ at initial presentation $(\mathrm{p}<0.001)$.

\section{Ammonia levels and complications}

Patients with ammonia levels above the derived cut off value of $124 \mu \mathrm{mol} / \mathrm{l}$ had a higher frequency of cerebral oedema $(p=0.020)$ and deeper encephalopathy grades at admission $(p=0.055)$. These patients also developed other complications such as need for ventilation $(p=<0.001)$, seizures $(p=0.006)$, and renal failure $(p=0.009)$ more often compared with patients with lower ammonia levels (table 2).

\section{Ammonia levels and cerebral dysfunction}

At presentation, patients with grade 3 or 4 encephalopathy had higher median ammonia levels than patients with grade 1 or 2 encephalopathy ( $148.3 \vee 105.0 \mu \mathrm{mol} / \mathrm{l}$, respectively; $\mathrm{p}=0.021$ ). Similarly, patients with clinical cerebral oedema at presentation had higher median ammonia levels than patients without overt cerebral oedema, although the difference did not reach statistical significance (156.0 v $119.0 \mu \mathrm{mol} / \mathrm{l} ; \mathrm{p}=0.064$ ).

\section{Ammonia levels and biochemical parameters}

No correlation was found between ammonia levels and aspartate aminotransferase, alanine aminotransferase, prothrombin time prolongation, $\mathrm{pH}$, bicarbonate, urea levels, or albumin. Only bilirubin levels were found to correlate with ammonia levels (Pearson's correlation coefficient 0.29, $\mathrm{p}=0.01)$.

\section{Seizures}

Seizures occurred in 18 patients (22.5\% overall, $43 \%$ among non-survivors). Seizures in these patients were recalcitrant to 
Table 2 Mortality, advanced encephalopathy, and complications in acute liver failure patients as a function of plasma ammonia levels

\begin{tabular}{|c|c|c|c|}
\hline Parameter & $\begin{array}{l}\text { Ammonia }<124 \mu \mathrm{mol} / \mathrm{l} \\
(\mathrm{n}=38)\end{array}$ & $\begin{array}{l}\text { Ammonia } \geqslant 124 \mu \mathrm{mol} / \mathrm{l} \\
(\mathrm{n}=42)\end{array}$ & p Value \\
\hline Mortality & $9(23.7)$ & $33(78.6)$ & $<0.001$ \\
\hline Renal failure & $1(2.7)$ & $10(23.3)$ & 0.009 \\
\hline Ventilation & $10(27.0)$ & $30(69.8)$ & $<0.001$ \\
\hline Infection & $19(51.4)$ & $28(65.1)$ & 0.212 \\
\hline Cerebral oedema & $8(21.6)$ & $20(46.5)$ & 0.020 \\
\hline Encephalopathy grade (3/4) & $23(62.2)$ & $35(81.4)$ & 0.055 \\
\hline Seizures & $3(8)$ & $15(35)$ & 0.006 \\
\hline
\end{tabular}

standard antiseizure medications and were uniformly fatal. All patients had features of cerebral oedema when seizures occurred, and no contributing metabolic factor was found. Patients admitted with higher ammonia levels had a significantly higher seizure incidence (table 2). Fifteen of $43(35 \%)$ patients with ammonia levels $\geqslant 124 \mu \mathrm{mol} / \mathrm{l}$ developed seizures compared with three of $37(8 \%)$ patients with ammonia levels $<124 \mu \mathrm{mol} / \mathrm{l}(\mathrm{p}=0.006)$.

\section{Ammonia levels and time to death}

Ammonia levels were not correlated with time to death among the non-survivors (Pearson's correlation coefficient $0.013, p=0.936$ ). The 23 patients who died early (within four days) and the 19 patients who died later had similar median ammonia levels at admission (172.9 $v 6 \quad 186.0 \mu \mathrm{mol} / \mathrm{l}$; $\mathrm{p}=0.723)$.

\section{Comparison of survivors and non-survivors}

Thirteen clinical and biochemical variables were found to significantly influence outcome on univariate analysis (table 3). Of these 13 variables, infection, need for ventilation, and renal failure developed in most patients subsequent to admission. Hence these three factors were excluded, and only those variables were included in the multivariate analysis that would be available at the initial evaluation. Additionally, since development of seizures was universally predictive of mortality, it could not be used as a covariate. A total of nine remaining variables were analysed using forward stepwise logistic regression analysis, taking death as the dependent variable (survival $=0$, death $=1$ ). These variables were dichotomised for best discrimination between survivors and non-survivors using cut off values derived by the construction of individual ROC curves (table 3 ). Three variables, arterial $\mathrm{pH} \leqslant 7.40$, presence of clinical cerebral oedema, and arterial ammonia levels $\geqslant 124 \mu \mathrm{mol} / \mathrm{l}$ were found to be significantly predictive of death on multivariate analysis. The adjusted OR and diagnostic accuracy of these three variables are given in table 3.

\section{Predicted probability of death}

Using the formula for $\mathrm{Z}$ values given earlier and the results of logistic regression, the derived value for $\mathrm{Z}$ was found to be:

$-2.53+2.91$ ammonia +2.41 oedema $+1.40 \mathrm{pH}$

\begin{tabular}{|c|c|c|c|c|c|c|}
\hline Variable & Survivors & $\begin{array}{l}\text { Non- } \\
\text { survivors }\end{array}$ & $\mathrm{p}$ Value & $\begin{array}{l}\text { Unadjusted OR } \\
(95 \% \mathrm{Cl})\end{array}$ & $\begin{array}{l}\text { Adjusted OR } \\
(95 \% \mathrm{CI})\end{array}$ & $\begin{array}{l}\text { Diagnostic } \\
\text { accuracy }\end{array}$ \\
\hline \multicolumn{7}{|c|}{ Clinical parameters } \\
\hline \multicolumn{7}{|l|}{ Age $(y)$} \\
\hline$<30$ & $31(81.6)$ & $25(59.5)$ & 0.032 & $3.0(1.1-8.4)$ & - & - \\
\hline$\geqslant 30$ & $7(18.42)$ & $17(40.5)$ & & & & \\
\hline \multicolumn{7}{|c|}{ Cerebral oedema } \\
\hline Absent & $33(86.8)$ & $19(45.2)$ & $<0.001$ & $8.0(2.6-24.5)$ & $12.6(1.5-108.5)$ & 70.0 \\
\hline Present & $5(13.2)$ & $23(54.8)$ & & & & \\
\hline \multicolumn{7}{|c|}{ Grade 3, 4 encephalopathy } \\
\hline Absent & $16(42.1)$ & $6(14.3)$ & 0.005 & $4.4(1.5-12.8)$ & - & - \\
\hline Present & $22(57.9)$ & $36(85.7)$ & & & & \\
\hline \multicolumn{7}{|c|}{ Biochemical parameters } \\
\hline \multicolumn{7}{|c|}{ Bilirubin (mg/dl) } \\
\hline$<15$ & $29(78.4)$ & $19(45.2)$ & 0.003 & $4.4(1.6-11.8)$ & - & - \\
\hline$\geqslant 15$ & $8(21.6)$ & $23(54.8)$ & & & & \\
\hline \multicolumn{7}{|c|}{ Albumin (mg/dl) } \\
\hline$\leqslant 3$ & $17(54.8)$ & $30(81.1)$ & 0.020 & $3.5(1.2-10.4)$ & - & - \\
\hline$>3$ & $14(45.2)$ & $7(18.9)$ & & & & \\
\hline \multicolumn{7}{|c|}{ PT increase (s) } \\
\hline$<25$ & $23(67.7)$ & $11(26.2)$ & $<0.001$ & $5.9(2.2-15.9)$ & - & - \\
\hline$\geqslant 25$ & $11(32.3)$ & $31(73.8)$ & & & & \\
\hline \multicolumn{7}{|c|}{ Bicarbonate $(\mathrm{mmol} / \mathrm{l})$} \\
\hline$\leqslant 20$ & $13(39.4)$ & $22(61.1)$ & 0.071 & $2.4(0.9-6.4)$ & - & - \\
\hline$>20$ & $20(60.6)$ & $14(38.9)$ & & & & \\
\hline \multicolumn{7}{|c|}{ - } \\
\hline$\leqslant 7.40$ & $4(12.50)$ & $14(38.9)$ & 0.014 & $4.5(1.3-15.5)$ & $6.6(0.8-57.5)$ & 61.8 \\
\hline$>7.40$ & $28(87.5)$ & $22(61.1)$ & & & & \\
\hline \multicolumn{7}{|c|}{ Ammonia $(\mu \mathrm{mol} / \mathrm{l})$} \\
\hline$<124$ & $29(76.3)$ & $9(21.4)$ & $<0.001$ & $11.8(4.1-33.8)$ & $10.9(5.9-284.0)$ & 77.5 \\
\hline$\geqslant 124$ & $9(23.7)$ & $33(78.6)$ & & & & \\
\hline
\end{tabular}

OR $(95 \% \mathrm{Cl})$, odds ratio (95\% confidence interval). 


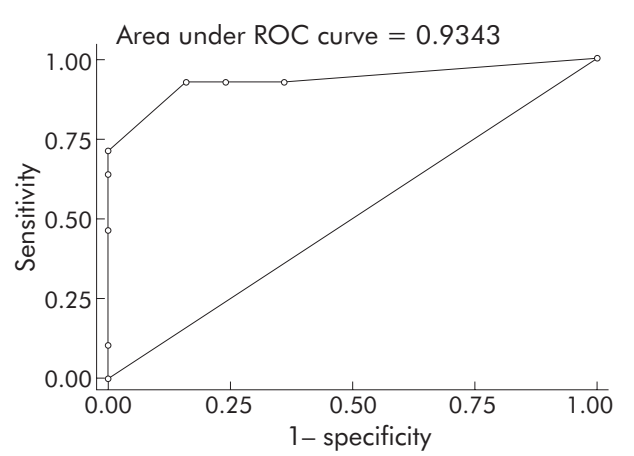

Figure 3 Receiver operating characteristic (ROC) curve of the predicted probability of death derived from the independent variables associated with mortality.

where ammonia was scored as 1 if it was $\geqslant 124 \mu \mathrm{mol} / \mathrm{l}$ and 0 if it was $<124 \mu \mathrm{mol} / \mathrm{l}$, oedema was scored as 1 if present and 0 if absent, and $\mathrm{pH}$ was scored as 1 if $\leqslant 7.40$ and 0 if $>7.40$.

The $\mathrm{Z}$ value was calculated for each case and the predicted probability of death was derived using the equation:

$\mathrm{P}_{\mathrm{X}}=\mathrm{l} /\left(\mathrm{l}+\mathrm{e}^{-\mathrm{Z}}\right)$

as described earlier. An ROC curve was made from the individual derived probability scores as the independent variable and mortality as the dependent variable. The area under the ROC curve was found to be 0.93 (fig 3).

\section{Comparative prognostic value of total ammonia and $\mathrm{pNH}_{3}$}

The prognostic value of $\mathrm{pNH}_{3}$ levels and total ammonia levels at admission was compared in 71 patients in whom simultaneous estimations were available. In common with total ammonia, median $\mathrm{pNH}_{3}$ levels were significantly higher among non- survivors compared with survivors $\left(9.00 \times 10^{-5} \mathrm{v}\right.$ $\left.4.73 \times 10^{-5} \mathrm{~mm} \mathrm{Hg} ; \mathrm{p}<0.001\right)$. From the ROC curves constructed with mortality as outcome variable, it was found that the area under the curve for both total ammonia and $\mathrm{pNH}_{3}$ levels were similar (fig 4). Additionally, by using multivariate logistic regression analysis the -2 log likelihood ratios for total ammonia and $\mathrm{pNH}_{3}$ were found to be 46.7 and 49.8 , respectively, which were not significantly different at two degrees of freedom.

\section{DISCUSSION}

We have defined the clinical utility of ammonia levels among patients with ALF. The advantage of our study cohort was its homogenous aetiology, with viral hepatitis as the cause in over $80 \%$ of cases (table 1), similar to previously reported studies from our centre. ${ }^{8}{ }^{16}$ In Western series, the aetiological profile of patients was heterogeneous. ${ }^{17-19}$ Drug induced and non A-E hepatitis induced ALF have been repeatedly associated with a poorer prognosis. ${ }^{20}{ }^{21}$ In addition, a uniform treatment protocol was followed in all cases. No patient was given enteral feedings for the initial 72 hours, or ammonia lowering therapies, which would have confounded interpretation of ammonia levels. In the only published human study relating ammonia to outcome, all patients were already on lactulose when ammonia levels were estimated, and a subgroup was being treated with $\mathrm{N}$-acetyl cysteine. ${ }^{5}$ Liver transplantation was not available at our centre at the time of study, and all patients were followed up to survival or demise. Such studies would not be ethically possible at Western centres.

We found that ammonia levels at admission were significantly higher among non-survivors than survivors (fig 1, table 3). The majority of the patients were stratified for mortality risk by a cut off ammonia level of $124 \mu \mathrm{mol} / \mathrm{l}$

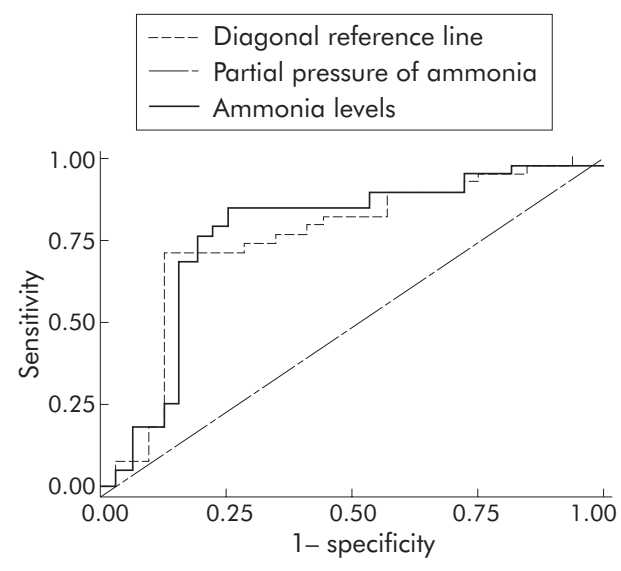

Figure 4 Receiver operating characteristic curves of total ammonia and partial pressure of ammonia levels, and mortality in 71 acute liver failure patients. Area under the curve for total ammonia was $0.77(95 \%$ confidence interval (Cl) $0.65-0.89$ ) and for partial pressure of ammonia $0.76(95 \% \mathrm{Cl} 0.65-0.88)$.

(fig 2). This observation was further supported by the fact that those patients whose ammonia levels were above $124 \mu \mathrm{mol} / \mathrm{l}$ within 24 hours of hospitalisation had advanced encephalopathy, a higher frequency of overt cerebral oedema, renal failure, infection, and seizures. Each of these complications was associated with higher mortality among ALF patients (table 2). Clemmesen et al had reported higher ammonia levels in 14 patients with ALF related to acetaminophen toxicity, who later died from cerebral herniation, than in 30 patients who survived. They found ammonia levels of $\geqslant 146 \mu \mathrm{mol} / \mathrm{l}$ to be predictive of subsequent cerebral herniation. $^{5}$ This was an arbitrary level which was chosen because all patients who developed cerebral herniation had ammonia levels higher than this level. No estimates of predictive accuracy were provided. Furthermore, their time of ammonia estimation was within 24 hours of developing grade 3 encephalopathy. ${ }^{5}$ While the time trends in ammonia levels among ALF patients remain undefined, we found that ammonia levels at admission itself can be used to predict subsequent outcome. From a clinical viewpoint, it is encouraging that single arterial ammonia estimations can be so informative. However, multiple factors can influence ammonia values, and a wide range of ammonia levels were found. In the present study, $18.8 \%$ of patients had ammonia levels within normal limits at presentation. Thus a single normal ammonia value may not rule out the diagnosis of ALF, or portend a favourable prognosis. More frequent ammonia estimations may further refine the conclusions determined in the present study.

Using logistic regression analysis, arterial $\mathrm{pH}$, presence of cerebral oedema, and arterial ammonia levels at admission were predictive of mortality (table 3 ). We excluded infection, need for ventilation, and renal failure because these factors were absent at the time of hospitalisation, and any mortality estimate incorporating these three variables would require following the entire clinical course of the patient. Such risk estimates would lack any practical utility. In our patients, initial presentation with renal failure or sepsis was infrequent, and these complications usually developed later.

The adjusted OR for mortality attributable to ammonia was 10.9, which was similar to the OR of overt cerebral oedema in the present study (table 3 ). The latter complication in ALF has been documented as the major cause of death. $.^{5} 818-22$ Therefore, arterial ammonia levels may be used to identify high risk patients for mortality during the early course of the illness. From the multivariable analysis, a quantitative 
estimate of mortality risk was derived, and was found to adequately differentiate non-survivors from survivors. This is depicted in fig 3, which illustrates the fit of the model. However, the predictive ability of any score is expected to be high when validated on the dataset used to generate the score. Thus our prognostic model must be validated prospectively in an external dataset. Another limitation of our study was the small sample size available for analysis. This means that our study had reduced power to detect effects of a moderate size.

Prognostic criteria for ALF have been reported from both the East and West. ${ }^{22}$ Both King's College and Clichy criteria had a positive predictive value of 0.89 and negative predictive values of 0.47 and 0.36 , respectively, when assessed in nontransplanted patients with non-paracetamol induced ALF. ${ }^{23}$ No prognostic model to date has incorporated ammonia levels. Any refinement of mortality estimate of ALF patients would be of immense utility to allocate expensive treatment options, such as liver transplantation. This model also illustrates the fundamental conclusion drawn from this study, that higher ammonia levels confer higher mortality risk (table 2, fig 1 ).

Prolongation of prothrombin time has been identified as one of the important prognostic variables among patients with ALF in many studies. However, in the present study, multivariate analysis did not find it to be an independent predictor of mortality. It is possible that due to the smaller sample size of the present study compared with previous reports $^{819-21}$ the association of prothrombin time prolongation with outcome was not evident. Furthermore, none of the previous studies included ammonia as a covariate of mortality. Arterial ammonia may have a stronger association with outcome than prothrombin time, and may have masked the influence of the latter factor, particularly when the sample size was small in which only robust influencing factors of prognosis are likely to be identified.

It has been stated that a relationship between biological toxicity of ammonia and $\mathrm{pH}$ of the milieu is "universal throughout nature from onion to man". ${ }^{6}$ However, $\mathrm{pNH}_{3}$ was not superior to total arterial ammonia levels for prognostic purposes among our ALF patients. As estimation of the former is more cumbersome, total ammonia levels may suffice for the purpose of risk stratification.

Despite the extensive supporting experimental literature, the uncertain role of ammonia is reflected by the fact that hepatology textbooks still state that therapies to lower ammonia are of no use in ALF. ${ }^{24-27}$ While targeting the gut to lower ammonia production by lactulose or antibiotics may be too slow to influence the outcome in ALF, increasing peripheral utilisation of ammonia by ornithine aspartate or sodium benzoate may be useful. Rose et al reported that ornithine aspartate infusion resulted in normalisation of plasma ammonia and a significant decrease in brain water content in rats with ALF. ${ }^{28}$ No comparable human data exist.

There is significant unidirectional blood to brain transfer of ammonia in ALF, with brain-blood ammonia ratios increased fourfold or more. ${ }^{29}$ Measures such as hypothermia, which reduces this cerebral uptake of ammonia, have been documented to decrease cerebral oedema and improve encephalopathy. ${ }^{10}$ Therefore, higher ammonia levels may lead to a greater degree of cerebral dysfunction in ALF. We found significantly higher ammonia levels among patients with deeper encephalopathy, as expected. While seizures have been commonly reported in congenital hyperammonaemic syndromes, they are rarely reported in ALF. ${ }^{31-33}$ We do not routinely paralyse or sedate ALF patients, and have observed a high frequency of seizures among our ALF patients. ${ }^{9}$ In this study, patients with ammonia levels $\geqslant 124 \mu \mathrm{mol} / \mathrm{l}$ at admission had increased seizure frequency (table 2). It is likely that this cut off value of ammonia identified patients with advanced cerebral dysfunction. More direct evidence is required to link ammonia levels and seizures in patients with ALF.

In summary, we have demonstrated that high arterial ammonia levels, measured within 24 hours of patient presentation, are associated with a worse outcome among patients with ALF. Our findings encourage viewing ALF as a "hyperammonaemic state", and provide a rational background for the use of ammonia lowering therapies.

\section{Authors' affiliations}

V Bhatia, S K Acharya, Department of Gastroenterology, All India Institute of Medical Sciences, New Delhi, India

R Singh, Department of Biostatistics, All India Institute of Medical Sciences, New Delhi, India

Conflict of interest: None declared.

\section{REFERENCES}

1 Jalan R, Olde Damink SWM, Deutz NEP, et al. Moderate hypothermia for uncontrolled intracranial hypertension in acute liver failure. Lancet 1999:354:1164-8.

2 Strauss GI, Knudson GM, Kondrup J, et al. Cerebral metabolism of ammonia and amino acids in patients with fulminant hepatic failure. Gastroenterology 2001:121:1109-19.

3 Hazell AS, Butterworth RF. Hepatic encephalopathy: An update of pathophysiologic mechanisms. Proc Soc Exp Biol Med 1999;222:99-112.

4 Felipo V, Butterworth RF. Neurobiology of ammonia. Prog Neurobiol 2002:67:259-79.

5 Clemmesen JO, Larsen FS, Kondrup J, et al. Cerebral herniation in patients with acute liver failure is correlated with arterial ammonia concentration. Hepatology 1999;29:648-53.

6 Warren K, Nathan DG. Passage of ammonia across blood-brain barrier and its relation to blood $\mathrm{pH}$. J Clin Invest 1958:37:1724-8.

7 Tandon BN, Bernauau J, O Grady J, et al. Recommendations of the International Association for the Study of the Liver Subcommittee on nomenclature of acute and sub acute liver failure. J Gastroenterol Hepatol 1999;14:403-4.

8 Acharya SK, Dasarathy S, Kumer TL, et al. Fulminant hepatitis in a tropical population: clinical course, cause and early predictors of outcome. Hepatology 1996;23:1448-55.

9 Bhatia V, Batra Y, Acharya SK. Prophylactic phenytoin does not improve cerebral edema or survival in ALF-a controlled clinical trial. $J$ Hepatol 2004;41:89-96

10 Riegler JL, Lake JR. Fulminant hepatic failure. Med Clin North Am 1993;77:1057-83.

11 Nanda SK, Yalchinkaya K, Panigrahi AK, et al. Etiological role of hepatitis 'E' virus in sporadic fulminant hepatitis. J Med Virol 1994;42:133-7.

12 Jameel S, Durgapal H, Habibullah CM, et al. Enteric non A, non B hepatitis: epidemics, animal transmission, and hepatitis $\mathrm{E}$ virus detection by the polymerase chain reaction. J Med Virol 1992;37:263-70.

13 Manning RT. A nomogram for estimation of $\mathrm{pNH}_{3}$. J Lab Clin Med 1964:63:297-8.

14 Altmann DG. Practical statistics for medical research. London: Chapman and Hall, 1991.

15 Kleinbaum DG, Klein M. Logistic regression. In: Dietz K, Gail M, Krickeberg K, et al. A self learning text, 2nd edn. New York: Springer Verlag, 2002:18

16 Acharya SK, Panda SK, Saxena A, et al. Acute liver failure in India: a perspective from the East. J Gastroenterol Hepatol 2000;15:473-9.

17 Ostapowicz G, Lee WM. Acute hepatic failure: A western perspective. J Gastroenterol Hepatol 2000;15:480-8.

18 Hoofnagle JH, Carithers RL, Shapiro C, et al. Fulminant hepatic failure: summary of a workshop. Hepatology 1995;21:240-52.

19 Bernal W, Wendon J. Acute liver failure; clinical features and management. Eur J Gastroenterol Hepatol 1999;1:977-84

20 Bernau J, Rueff B, Benhamou JP. Fulminant and subfulminant liver failure: Definitions and causes. Semin Liver Dis 1986;6:97-106.

21 O'Grady JG, Alexander GJ, Hayllar KM, et al. Early indicators of prognosis in fulminant hepatic failure. Gastroenterology 1989;97:439-45.

22 Batra Y, Acharya SK. Acute liver failure: prognostic markers. Indian J Gastroenterol 2003;22(suppl 2):S66-8.

23 Pauwals A, Mostifa N, Florent C, et al. Emergency liver transplantation for acute liver failure: evaluation of London and Clichy criteria. $J$ Hepatol 1994;17:124-7.

24 Sanyal AJ, Stravitz RT. Acute liver failure. In: Zakim D, Boyer TD, eds. Hepatology: a textbook of liver disease. Philadelphia: Saunders, 2003:445-96.

25 Bernau J, Benhamou JP. Fulminant and subfulminant liver failure. In: Bircher J, Benhamou JP, Mclntyre N, et al. Oxford textbook of clinical hepatology. New York: Oxford Medical Publications, 1999:1341-71. 
26 Williams R, Riordan. Fulminant hepatic failure. In: Schiff ER, Sorrel MF Maddrey WC, eds. Diseases of the liver. Philadelphia: Lippincott Williams and Wilkins, 2003:941-70.

27 Yee HF, Lidofsky SD. Acute liver failure. In: Feldman M, Friedman LS, Sleisenger $\mathrm{MH}$, eds. Gastrointestinal and liver disease. Philadelphia: Saunders, 2002:1567-76

28 Rose C, Michalak A, Rama Rao KV, et al. L-ornithine-L-aspartate lowers plasma and cerebrospinal fluid ammonia and prevents brain edema in rats with acute liver failure. Hepatology 1999;30:636-40.

29 Butterworth RF. Pathophysiology of hepatic encephalopathy: a new look at ammonia. Metab Brain Dis 2002;17:221-7.
30 Rose C, Michalak A, Pannunzio M, et al. Mild hypothermia delays the onset of coma and prevents brain edema and extracellular brain glutamate accumulation in rats with acute liver failure. Hepatology 2000;31:872-7.

31 Flannery DB, Hsia YE, Wsolf B. Current status of hyperammonemia syndromes. Hepatology 1982;2:495-506.

32 Blei AT. Medical therapy of brain edema in fulminant hepatic failure. Hepatology 2000;32:666-9.

33 Blei AT. Cerebral edema and intracranial hypertension in acute liver failure: distinct aspects of the same problem. Hepatology $1991 ; 13: 376-9$.

\section{EDITOR'S QUIZ: GI SNAPSHOT}

\section{Gastrointestinal bleeding: don't overlook the role of the pancreas}

\section{Clinical presentation}

A 59 year old man was admitted with a three day history of haematemesis and malaena. He was known to suffer from hyperlipidaemia and type II diabetes. He had a history of acute gall stone pancreatitis complicated by pseudocyst formation and treated with an open cystgastrostomy in 1996. He drank less than 20 units of alcohol/week and was a non-smoker. His medication included aspirin, metformin, and simvastatin. On admission he was hypotensive (90/70 mm Hg) and tachycardic. There were no clinical signs of stigmata of chronic liver disease. Abdominal examination was unremarkable. On admission, haemoglobin was $4.4 \mathrm{~g} / \mathrm{dl}$, international normalised ratio 1.4 , urea $21.2 \mathrm{mmol} / \mathrm{l}$, and glucose $30.4 \mathrm{mmol} / \mathrm{l}$. The patient was resuscitated with blood and intravenous crystalloid and underwent an urgent upper gastrointestinal endoscopy followed by an abdominal computed tomography (CT) scan.

\section{Question}

What does the duodenal endoscopic image (fig l) demonstrate? What is shown on the abdominal CT scans (figs 2, 3)? See page 113 for answer

This case is submitted by:

G W Moran

M S H Smith

J R Butterworth

Department of Gastroenterology, Royal Shrewsbury and Telford Hospital NHS Trust, Telford, UK

Correspondence to: Dr G W Moran, Department of Gastroenterology, Royal Shrewsbury and Telford Hospital NHS Trust, Apley Castle, Telford TF1 3QD, UK; gwmoran@hotmail.com doi: 10.1136/gut.2005.070037

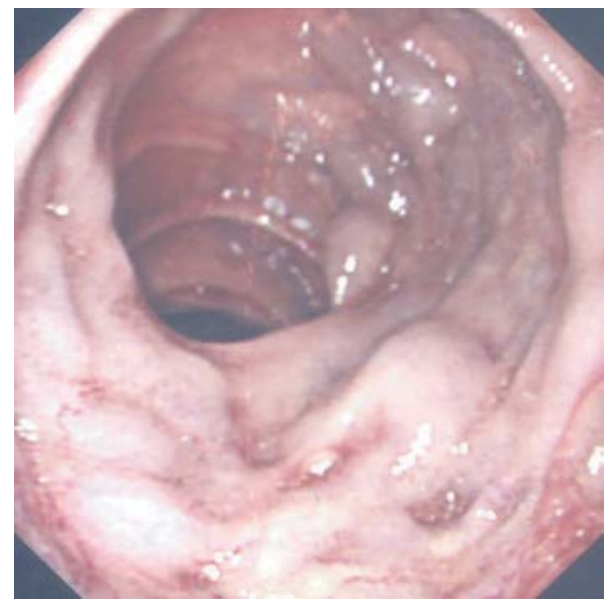

Figure 1 Endoscopy of the proximal duodenum.

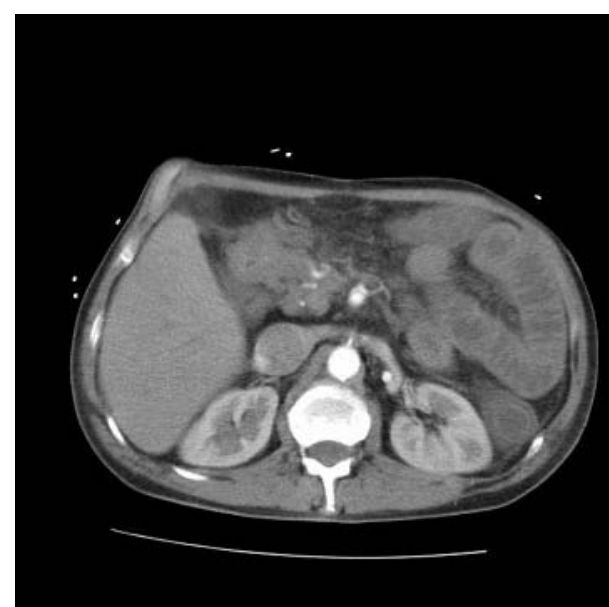

Figure 2 Computed tomography scan of the abdomen.

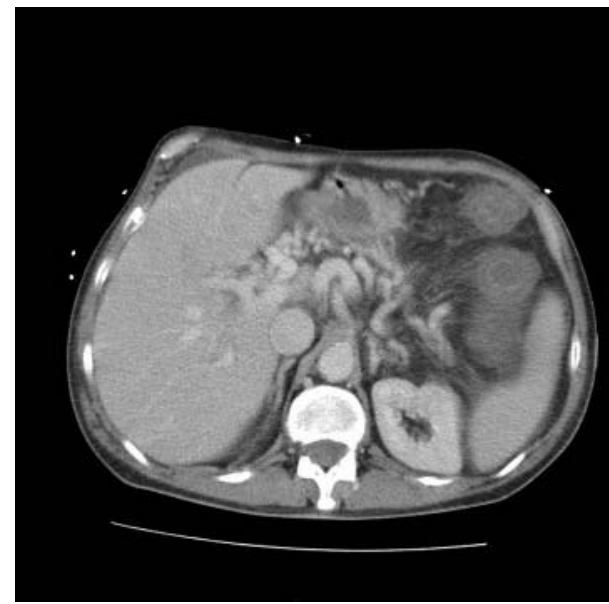

Figure 3 Computed tomography scan of the abdomen (portal venous phase). 